\title{
El acoso terrorista al centro-derecha durante la Transición a la democracia. El aislamiento político de la Unión del Centro Democrático en el País Vasco
}

\section{Terrorist pressure over the center-right during Transition to Democracy. The political Isolation of Unión del Centro Democrático (UCD) in the Basque Country}

\author{
Manuel MonTERo \\ Universidad del País Vasco \\ manuel.montero@ehu.eus \\ https://orcid.org/0000-0002-1905-9323
}

Fecha de recepción: 01-07-2020

Fecha de aceptación: 10-11-2020

\section{RESUMEN}

Este artículo estudia el impacto que durante la Transición tuvo el terrorismo en el centroderecha del País Vasco. Tiene en cuenta el acoso de ETA a UCD y las formas que adoptó la propagación del terror, entre ellas las derivadas de los silencios sociales y de los apoyos que obtuvo. En las postrimerías del franquismo, la presión terrorista hizo que disminuyese la presencia pública de este ámbito ideológico, gestando así deficiencias en el pluralismo político vasco. En este proceso influyeron algunos conceptos: la relativización del terrorismo, entendido como una parte más del juego político, y la idea generalizada de que el principal medio para reducirlo era la adopción de medidas autonomistas, lo que incrementó su influencia en el proceso de descentralización. Al aislamiento del centro político contribuyeron planteamientos de los grupos antifranquistas, para los que los avances democráticos y autonómicos eran logros arrancados, no metas compartidas.

Palabras clave: Transición a la democracia, ETA, UCD, terrorismo Topónimos: España, País Vasco

Período: 1977-1982

\section{ABSTRACT}

This article studies the impact of terrorism on the Basque Country's centre-right during the Transition. ETA's persecution of UCD is taken into account, as well as the different forms of propagation of terror, such as those related to social silences and support for this strategy. In the final years of Francoism, terrorist pressure led to reduced public presence in this ideological sphere. This resulted in shortcomings in Basque political pluralism. A number of concepts influenced this process: the relativization of terrorism, understood as another element of the political game, and the 
generalized idea that the main means of reducing it was the adoption of autonomist measures, which increased their influence in the process of decentralization. The isolation of the political centre was heightened by the proposals of anti-Francoist groups, for whom democratic and autonomic progress were achieved by force, not shared objectives.

Key words: Transition to Democracy, ETA, UCD, terrorism

Toponyms: Spain, Basque Country

Period: 1977-1982

\section{INTRODUCCIÓN}

En la Transición a la democracia fue crucial el acoso del terrorismo. ETA alcanzó aquellos años su mayor actividad criminal, condicionando la vida del País Vasco a la salida de la dictadura franquista. Atacó a las fuerzas de seguridad y a amplios sectores sociales, en particular al centro-derecha, que sufrieron con intensidad el acoso del terror.

Esta situación tuvo notables efectos sociales y políticos. Condicionó la descentralización autonómica, objeto de las exigencias del terrorismo y de sus grupos afines. La autonomía vasca quedó asociada también al combate contra el terrorismo.

El impacto del terror en el centro-derecha resultó decisivo en el desenvolvimiento local de la Transición. Propició su retraimiento político, así como su aislamiento, debido a los comportamientos desencadenó la acción de ETA. Influyeron también las posiciones que adoptaron grupos que se distanciaban del terror pero que no advirtieron algunos efectos que producía en la democracia.

La alta conflictividad vasca desde los últimos años del franquismo "tiene su máxima expresión en la existencia de un grupo terrorista, ETA [...] y se manifiesta también en la falta de consenso entre las principales fuerzas políticas y sociales sobre el encaje territorial de Euskadi (o su separación) en el conjunto de España"1. Este artículo tendrá en cuenta también las actitudes que adoptaron distintos componentes de la política vasca. El marco, condicionado por ETA, gestó un ambiente convulso que explica las anomalías del País Vasco durante la Transición.

Esta investigación tiene como punto de partida el análisis de la prensa del periodo, particularmente la del País Vasco. Esta fuente permite sobre todo reconstruir el ambiente social que rodeó a los atentados, una cuestión crucial para entender el concreto impacto del terrorismo. Así mismo, se tienen en cuenta las posiciones de los distintos partidos políticos y la bibliografía referida al fenómeno ETA, que ha crecido notablemente los últimos años.

\section{ETA CONTRA UCD}

"Somos impotentes ante la sensación de que nos están cazando como conejos"2. Lo decía el presidente de la Unión del Centro Democrático de Guipúzcoa el 12 de mayo de 1980. ETA había asesinado a Ramón Baglietto, militante del partido. La expresión no fue acogida con sorpresa, pues reflejaba bien las circunstancias, que explican parte de la política centrista.

1 F. J. Merino Pacheco, La izquierda radical ante ETA. ¿El último espejismo revolucionario de Occidente?, Bilbao, Bakeaz, 2011, p. 49.

2 Declaraciones de Jaime Mayor Oreja, secretario general de UCD en Guipúzcoa, a la agencia EFE, "Asesinado un simpatizante de UCD", La Gaceta del Norte, 13 de mayo de 1980. 
La semblanza biográfica de Baglietto nos sitúa en el paisaje humano de la UCD vasca. Natural de Azkoitia, su padre había sido carlista. Estudió decoración, fue teniente alcalde y antes de la Transición se implicó en actividades políticas de la mano de Marcelino Oreja. Después, participó en la formación de la UCD en Guipúzcoa, un pequeño grupo de militantes. Su actividad política consistió en tareas básicas: meter papeletas en los sobres, encartar propaganda...

Lo cuenta su viuda, Pilar Elías: "Nunca sentimos miedo, ese pánico relacionado con la muerte, [...] jamás la ETA había tocado a nadie de UCD"3. La impresión no era del todo certera, pues el terrorismo había asesinado ya a un simpatizante de UCD.

Baglietto no tenía cargo público ni ingresos derivados de la política, que le estaba costando esfuerzo y dinero, y que en el tenso ambiente guipuzcoano exigía idealismo. Su origen carlista no pudo determinar que le señalasen, pues en el mismo caso se hallaban dirigentes nacionalistas y miembros del nacionalismo radical. ETA le acusó de "confidente" y "enemigo del pueblo trabajador vasco", así como de «su estrecha relación personal y política con el ministro de Asuntos Exteriores, Marcelino Oreja ${ }^{4}$. Como las dos primeras imputaciones eran rutinarias, le hacía "culpable" su vinculación a la UCD. Su muerte amenazaba a quienes compartían filiación política.

Seguramente Baglietto disfrutaba de una buena inserción en el ámbito donde se movía, pues sus negocios - la decoración de viviendas y una tienda de muebles - lo exigían. No obstante, para amplios sectores sociales, la UCD era un partido franquista. Genéricamente el centro-derecha estaba estigmatizado como enemigo, algo crucial cuando una organización armada se decía en guerra..., y parte de la sociedad vasca compartía tal imaginario.

Por entonces las condenas al terrorismo quedaban circunscritas al ámbito inmediato, si las había. La (relativa) novedad de que habían asesinado a una persona por formar parte de un partido democrático no cambió las tornas. La condena quedó circunscrita al Ayuntamiento de Azkoitia. Fue unánime, con los votos del PNV, HB y PSOE (UCD no tenía concejal). Muestra las confusas categorías que se utilizaban. No mencionaba al crimen ni al asesinado, envueltos en la genérica "continua e incesante violencia". "Este Ayuntamiento [...] condena una vez más este clima de violencia y exige su cese con la adopción de las vías políticas para la reconstrucción de nuestro país"5. Implícitamente, rechazaba actuaciones policiales contra el terrorismo mientras la propuesta de vías políticas se asemejaba al camino marcado por ETA. Tan precario planteamiento era saludado como una condena de HB "a ETA militar"6. Así lo interpretó el alcalde, Román Sudupe, que entendía se acercaba al PNV.

El primer asesinato cometido por ETA tras formarse el Gobierno Vasco el 9 de abril de 1980 fue el de Eugenio Lázaro Valle, jefe de la policía municipal de Vitoria, el 13 de abril. El lehendakari lo condenó sin mencionar a ETA ni designar al terrorismo por tal nombre; el crimen se convertía en "acto de violencia". Incluía una apostilla. "Pido al pueblo vasco un posicionamiento coherente y firme con su voluntad favorable a la legalidad estatutaria en contra de la violencia"7. La condena a la violencia se asociaba a los avances autonomistas.

Cuando unos días después ETA asesinó a dos guardias civiles en la frontera de Irún ya no hubo comunicado gubernamental. El único partido que se posicionó fue la UCD

3 P. Elías, Ramón Baglietto Martínez, Euskal Ikasketetarako. Fundación Popular de Estudios Vascos, www. fpev.es

4 "ETA $(\mathrm{m})$ reivindica el atentado", El Diario Vasco, 14 de mayo de 1980.

5 "El Ayuntamiento de Azcoitia condena", El Diario Vasco, 14 de mayo de 1980.

6 "También Herri Batasuna condena a ETA militar", Diario 16, 15 de mayo de 1986.

7 "Condena de Garaikoetxea tras atentado", El Diario Vasco, 15 de abril de 1980. 
guipuzcoana, que añadió a la condena un diagnóstico. Aseguraba que combatir la violencia requería aislar a quienes la ejercen, propugnan o encubren.

Por aquellos días hizo pública su postura ante la violencia, sin mencionar a ETA ni incluir el término "terrorismo", subsumidos en "actos contrarios a la dignidad de la persona humana y a los derechos inviolables inherentes a la vida humana".

Tales circunstancias enmarcan el impacto del terrorismo en la política centrista. La UCD guipuzcoana, que tuvo dificultades para constituirse, quedó reducida a cenizas. Los asesinatos de Luis Candendo (9 de noviembre de 1978), Ramón Baglietto (11 de abril de 1980), Jaime Arrese (23 de octubre de 1980), José Ignacio Ustaran (30 de septiembre de 1980) y Juan de Dios Doval (31 de octubre de 1980) ${ }^{9}$ crearon una situación crítica. Imposibilitaba el funcionamiento de UCD como organización política con irradiación social.

El primer miembro de UCD asesinado por ETA fue Candendo, oficial de primera de talleres mecánicos, trabajador de Altos Hornos de Vergara durante 22 años, muerto en atentado junto a su domicilio de Anzuola. "Nunca, que nosotros sepamos, ha estado amenazado"10. No hay noticia de condenas. Al funeral sólo asistieron autoridades de UCD, la soledad de las víctimas en aquella época. Nada indica que hubiese sufrido aislamiento social. Si fue así, este empezó con la muerte, en un funeral desangelado. El comunicado de ETA, dos días después, no mencionaba las simpatías políticas; lo calificaba de "confidente y colaborador de las fuerzas represivas acantonadas en Euskadi", la rutina.

Para entonces el asesinato de Candendo había pasado a la historia. La noticia de la reivindicación se perdía entre las que mencionaban manifestaciones contra detenciones, la explosión de goma-2 en la librería "Donosti" de San Sebastián, bombas en Anzuola y el atentado de Zumárraga en el que murieron dos guardias civiles.

El panorama de las semanas anteriores al referéndum constitucional resultaba complicado. Hubo manifestaciones antiterroristas en toda España, tras la que el PNV había convocado en Bilbao dos semanas antes. En la de Barcelona algunos gritos, minoritarios, culpaban del terrorismo a "la UCD del País Vasco". Marcos Vizcaya explicaba el planteamiento del PNV respecto al terrorismo: ETA acabaría desapareciendo "por inanición", "porque sus planteamientos políticos no encontrarán el menor eco popular"11; el desarrollo autonómico acabaría con ETA, que, de seguirse el argumento, no requería un tratamiento policial. También los obispos vascos hicieron pública su posición ante la violencia. El "no matarás" quedaba asociado a una necesidad política: "sin el respeto a la vida no es posible fundamentar ni la paz, ni el derecho de los pueblos". La paz se asociaba al derecho de los pueblos. Difundía la imagen de que en el País Vasco se enfrentaban dos bandos —con los riesgos de "una escalada de acciones y reacciones, lesivas de los derechos humanos"-, lo que menoscababa las responsabilidades de ETA. El exordio final, que querría mostrar imparcialidad, refleja la vaguedad con que se abordaba la cuestión terrorista. Expresaban "un sincero amor cristiano a los que matan y a los que mueren"12. ¿Matar y morir, dos caras de la misma moneda, éticamente equiparables?

8 "Importante llamamiento del consejero de Interior a todos los habitantes del País Vasco", La Gaceta del Norte, 14 de mayo de 1980.

9 "Ya son cinco los miembros de UCD asesinados por ETA", ABC, 1 de noviembre de 1980. El artículo mencionaba además dos secuestros y un intento de secuestro sobre diputados de UCD.

10 La Gaceta del Norte, 11 de noviembre de 1978.

11 "El PNV, contra los 15 puntos de Martín Villa", El Correo, 11 de noviembre de 1978.

12 “¡Basta de sangre!”, El Diario Vasco, 12 de noviembre de 1980. El artículo cita una pastoral de los obispos de Bilbao y San Sebastián publicada el día anterior. 


\section{EL IMPACTO SOCIAL Y POLÍTICO DEL TERRORISMO EN EL CENTRO- DERECHA. LOS MECANISMOS DEL TERROR}

El problema que planteó a la UCD el terrorismo no fue sólo acoso a sus militantes. Estaba el sistemático acoso a las fuerzas del orden: "la presión sobre los cuerpos policiales, más que agobiarlos, debía sumirlos en una atmósfera irrespirable"13. El brutal clima que creó queda reconstruido por Estela $\mathrm{Baz}^{14}$. Y jugó un papel propio la persecución contra el centro y derecha no nacionalista, comenzada a finales de la dictadura. "Las campañas 'antialcaldes' y 'antichivatos' le sirvieron a ETA y su trama política para depurar el censo electoral y a la sociedad vasca"15. Incluyó el asesinato de presidentes de las diputaciones de Guipúzcoa y Vizcaya en 1976 y 1977, militantes carlistas y miembros de Alianza Popular. Al tiempo, se produjo la agresión terrorista a las fuerzas del orden, al ejército, a algunos alcaldes (los de Oyarzun y Galdácano resultaron asesinados) y profesionales diversos, acusados de confidentes policiales o de no pagar la extorsión que se llamó "impuesto revolucionario". De no mediar un estigma expreso, bastó la condena social a posteriori, "algo habrá hecho". El crimen tenía respaldo, aquiescencia o suscitaba temor suficiente para infundir silencio.

La agresión terrorista alcanzó su mayor virulencia en 1978, 1979 y 1980, con 65, 86 y 93 muertes, "gran parte de ellos asesinados por sus ideas o por lo que simbolizaban, por su relación con el Estado y con la nación española [...] con los que se buscaba no sólo eliminar a las personas físicas sino también a lo que representaban, la nación española"16. Su ataque no fue un enfrentamiento armado en una especie de escenario bélico, un aséptico duelo entre el Estado y un grupo violento. Tampoco una guerra, conforme al imaginario que lo presenta como parte de un conflicto secular. Tuvo una naturaleza propia, diferente a tales estereotipos. El terrorismo alcanzó gran penetración social. Contó con apoyos del nacionalismo radical, que se hizo hegemónico en algunos barrios, poblaciones, comarcas y ámbitos sociales. Tuvo la discrepancia pero también la comprensión del nacionalismo moderado. E, inicialmente, la oposición antifranquista — no sólo del País Vasco— entendía que todos compartían nociones políticas. Influyó la fascinación y/o el miedo que producen el miedo y la violencia.

Muestra las actitudes que gestaba el terror lo sucedido en el asesinato de Julio Martínez Ezquerro el 16 de diciembre de 1977. Se había iniciado ya el proceso democrático; a mediados de año, cuando las elecciones del 15 de junio, no había presos de ETA, por el indulto. Comenzaba la escalada del terror, pero aún no se había producido la acumulación de atentados que podría justificar algunos comportamientos.

Martínez Ezquerro era concejal de Irún. Aún no se habían realizado las elecciones municipales y en ese Ayuntamiento quedaban cuatro munícipes de la última corporación designada durante la dictadura; el resto había dimitido. La víspera del día que mataron a Julio habían decidido dimitir para dar paso a una gestora. Había ganado el PSOE (11.100 votos), seguido a distancia por el PNV (3.500). AP alcanzó los 2.700 , muy por delante de EE, por entonces una coalición nacionalista radical, con 1.800 votos.

El concejal había pertenecido a la guardia de Franco y regentaba un quiosco. En una localidad en la que el nacionalismo radical tenía poco peso, seguramente no había sido

13 L. Silva, M. Sánchez y G. Araluce, Sangre, sudor y paz. La guardia civil contra ETA, Barcelona, Península, 2017, p. 95.

14 E. Baz, Los niños de Lemóniz, Barcelona, Espasa, 2019.

15 G. Angulo, La persecución de ETA a la derecha vasca. Amenazas, exilio, extorsión y asesinatos, Córdoba, Almazara, 2018, p. 11.

16 L. Castells, "La transición en el País Vasco (1975-1980)", en J. P. Fusi y J. A. Pérez, Euskadi 1960-2011, Madrid, Biblioteca Nueva, 2017, p. 84. 
objeto de un proceso de aislamiento social, pues hubiese repercutido en su medio de vida. "Que yo sepa, no había recibido amenazas"17, explicó su suegra, en una entrevista propia de la época, en la que las víctimas quedaban "invitadas" a dar su versión de los hechos como meros observadores: esa mezcla de drama vital y banalización caracterizó a los años de plomo. Su suegro "era carabinero y ya sabe usted lo que pasa": el diagnóstico evocaba un mundo oscuro de maledicencias. Aun así, "vivían sin malos quereres", concluyó el periodista. "Se decía que estaba en una lista negra de ETA"18, trasmitió la viuda, confirmando la existencia del entorno tenebroso.

El terror estaba llevando a una sima ética: eso se desprende de lo que sucedió en el atentado. Le habían disparado junto a su casa y bajó su mujer, que hubo de asistir impotente a cómo se desangraba. Se acercaron varios transeúntes, pero quedaron pasivos, mirando. La mujer pidió ayuda para mover al hombre, pero nadie le echó una mano. Alguno comentó que había que esperar al juez. La escena duró cinco o diez minutos y esa imagen de un grupo impasible — ¿meros espectadores, curiosos, temerosos, avergonzados?retrata el deterioro moral: entenderían que había disparado ETA y que estaban ante un enemigo del pueblo vasco; o que la precaución exigía pasividad. Los odios o inquietudes eran profundos, incluso donde los apoyos al terrorismo eran electoralmente escasos. Los conceptos deshumanizadores habían calado.

Al final intervino un gitano, Pedro Valdés, que vivía cerca, ayudó a la mujer y llevó al herido al hospital, donde llegó ya fallecido. “¿Vio alguien a los agresores?”. "Verlos los vería mucha gente, pero nadie dice nada", declaró la mujer. La ley del silencio formó parte del caldo de cultivo del terror. Era relación causa/efecto de carácter simbiótico, pues el terror y el silencio se retroalimentaban; el silencio no fue neutral.

El terror no significó sólo una banda armada con capacidad destructiva sino también una sociedad que desarrolló comportamientos que posibilitaban su propagación. Además, lo admitía como parte del juego político y asumía, de grado o por miedo, el sectarismo belicista de ETA.

El mundo vecinal no estaba por el heroísmo ni la solidaridad con las víctimas. Tampoco hubo una reacción política ante el crimen. Al día siguiente se reunía la Asamblea de Parlamentarios. Hubo sólo una alusión al crimen. El presidente, el nacionalista Irujo, abrió la sesión "condenando las víctimas mortales de Tenerife, Málaga e Irún". La acción de ETA quedaba subsumida en un brote general de la violencia que incluía la muerte del estudiante Fernández Quesada en la Universidad de la Laguna en un lamentable enfrentamiento en el que disparó un guardia civil. El asesinato por ETA de un concejal franquista de Irún no suscitaba una reacción específica entre los parlamentarios vascos. Quizás no atisbaban la gravedad que para los vascos tenían estos sucesos o los integraban dentro de una especie de normalidad.

\section{LA UCD EN EL PAÍS VASCO}

En los proyectos de cambio que encabezó Suárez estuvo pronto la necesidad de la descentralización. Se derivaba de la presión que llegaba de Cataluña y del País Vasco, en este caso agigantada por el terrorismo y el protagonismo de ETA tras el asesinato de Carrero Blanco en diciembre de 1973. Además, toda la oposición antifranquista asumía las reivindicaciones autonomistas, sin desechar la idea de la autodeterminación.

17 "Anoche: asesinado un concejal en Irún", La Gaceta del Norte, 17 de diciembre de 1977.

18 "Según su esposa", El Diario Vasco, 18 de diciembre de 1977. 
Si UCD era imprecisa al definir la democracia a la que llegar, contaba con el modelo europeo. Además, para ello tenía la colaboración de los países occidentales. La descentralización planteaba problemas propios. Suscitaba temores de ruptura de España, con los consiguientes riesgos en sectores claves como el ejército o la derecha conservadora. El problema lo agudizaba el independentismo del que hacían gala algunos nacionalistas. Además, debía acometerse con premura —para integrar en el sistema a los nacionalismossin experiencias internacionales similares ni un modelo europeo al que seguir. Por último, las democracias europeas simpatizaban con la imagen de los "patriotas separatistas", a los que veían como luchadores por la libertad incluso mucho después de la Transición. Así, la presión terrorista tenía el doble efecto de hacer acuciantes las medidas descentralizadoras y de acentuar los problemas que planteaba un proceso de este tipo.

En los últimos años del franquismo la acción terrorista aceleró la descomposición del régimen en el País Vasco, con actuaciones contra la élite empresarial y el acoso a la representación del Estado. El ataque terrorista a los empresarios no sólo arrancaba de posiciones ideológicas. También buscaba recursos económicos. ETA se financió básicamente a partir de secuestros (106 millones de euros), atracos (19 millones) y extorsión (21 millones) ${ }^{19}$. A la altura de 1977 aún eran pocos los secuestros perpetrados, pero propiciaban la extorsión económica. Fueron nueve, casi todos a empresarios. Alguno quiso condicionar la conflictividad laboral, pero la mayoría buscó una rentabilidad económica. El de Felipe Uharte proporcionó a la banda 50 millones de pesetas, el de Francisco Luzuriaga entre 8 y 25 millones. En el secuestro de Ángel Berazadi ETA solicitó 200 millones; por falta de acuerdo o por problemas en las negociaciones, terminó con el asesinato del empresario —Apala, dirigente de ETA: "tiradlo a la basura"-. En junio de 1977 se produjo el secuestro y asesinato de Javier Ybarra, tras días de tensión en los que los dirigentes bancarios decidieron no propiciar el pago a los secuestradores y el préstamo obtenido por la familia fue tardío o insuficiente. Así relataba la familia sus negociaciones con el comando Zaharra: "las exigencias que nos han hecho de mil millones de pesetas a cambio de la vida de nuestro padre están totalmente fuera de nuestros recursos" 20 . La muerte de Ybarra fue crucial. "Le secuestran y le asesinan por ser la cabeza pensante", fue "un golpe maestro de ETA" porque era "el ideólogo, el intelectual de Neguri"21. Cabe discutir si tenía tan destacado papel, no digamos la maestría del golpe, pero no los efectos del crimen. "A partir de entonces hay una diáspora, física, porque la gente se marcha, e intelectual, porque cada uno ya sólo piensa en nadar y guardar la ropa", en palabras de Juan Antonio Ybarra, hijo del asesinado22. Para Gregorio Morán, significó "el principio del fin"23 de la alta burguesía de Neguri. Y fue el momento en que se generalizó la cesión al chantaje.

La derecha vasca perdió su soporte tradicional, bien por marchar del País Vasco, bien por su fragmentación o para evitar la exposición pública ante la amenaza del terror. Lo había explicado el 24 de enero de 1977, Unceta Barrenechea, presidente de la Diputación de Vizcaya, en una carta airada al ministro: "en 1977 no se desea ser valiente, porque ya se sabe dónde se acaba"24. Fue publicada tras su asesinato, unos meses después.

19 F. Domínguez Iribarren, "La financiación del terrorismo en la democracia" en J. Ugarte Gastaminza (coord.), La bolsa y la vida. La extorsión y la violencia de ETA contra el mundo empresarial, Madrid, La Esfera de los Libros, 2017.

20 "Mensaje de la familia Ybarra a la opinión pública", El Diario Vasco, 15 de junio de 1977.

21 Gregorio Morán, Testamento vasco, Madrid, Espasa Calpe, 1988.

22 Entrevista de Casimiro García Abadillo en El Mundo, 28 de abril de 2004.

23 G. Morán, Los españoles que dejaron de serlo. Cómo y por qué Euskadi se ha convertido en la gran herida histórica de España, Barcelona, Planeta 1983, p. 332.

24 "Escrita hace un año", $A B C, 9$ de octubre de 1977. La misiva protestaba por la legalización de la ikurriña. 
En sus años postreros se debilitó la estructura del franquismo en el País Vasco: la élite empresarial se desentendía de la problemática local; el tradicionalismo, que perdió fuerza tras identificarse con el régimen, había envejecido, mientras las nuevas generaciones de ascendencia carlista evolucionaron hacia el nacionalismo; desde los años sesenta la Iglesia vasca se había desplazado hacia el nacionalismo, mostrando su comprensión de las posiciones radicales o participando de ellas; los funcionarios que representaban la presencia del Estado marcharon u optaron por el silencio.

De ahí las dificultades del centrismo en el País Vasco durante la transición. La UCD, un partido en la que medianos y altos funcionarios tuvieron peso notable, apenas pudo arraigar. "La UCD nunca tuvo en Euskadi el predicamento que conoció en otras regiones españolas entre 1977 y 1982. En Euskadi fue sobre todo un partido alavés"25. En Vizcaya y Álava tuvo una débil estructura, sin posiciones comunes: el foralismo alavés contrastó con la apuesta estatutaria de los dirigentes vizcaínos.

La formación de la UCD en Guipúzcoa refleja bien estas dificultades. En las elecciones de junio de 1977 no logró presentar candidatura en esta provincia. Sí concurrió al Senado Jaime Mayor Oreja, por Demócratas Independientes Vascos — de orientación democristiana-, que obtuvo algo menos del $5 \%$ de los votos. De una familia con tradición política, los años anteriores (1975-1976) había sido secretario de juventudes de la Asociación Católica de Propagandistas y era sobrino de Marcelino Oreja, Ministro de Exteriores. Presidió la UCD guipuzcoana al constituirse el 15 de octubre de 1977. La formaban personalidades locales con actividades políticas los años anteriores, sin relevancia provincial salvo su líder. Se presentaba ${ }^{26}$ como una opción reformista, respetuosa con algunos criterios que se imponían en la sociedad vasca: autonomismo, cultura vasca e integración de Navarra, junto a la condena de la violencia.

En la historia de la UCD guipuzcoana tales matices ideológicos fueron irrelevantes. Lo expresó Jaime Mayor, cuando contaba la formación del partido: "dos años después, solo quedábamos vivos mi tío y yo". "ETA fue matando a todos los demás, uno a uno". Fue una parte decisiva de esta historia. Contribuyó a que el centro y la derecha tuviesen una precaria existencia en el País Vasco de la Transición, pese a su peso notable peso histórico.

En la sociedad vasca el pluralismo era cojo. Su principal deficiencia —la inacción de la derecha y la escasa presencia del centro- constituía fruto de la presión violenta. "No ha cambiado nada. Aunque la amnistía fuera total, seguiremos practicando la lucha armada en tanto no se consiga la alternativa KAS y, más adelante, hasta que no se consiga un Estado socialista e independiente"27: el primer comunicado de ETA tras las elecciones democráticas presagiaba que el terrorismo iba a seguir y que afectaría a la Transición. Se confirmaba la idea de que "ETA parte del supuesto del que el pueblo vasco será libre [...] cuando obtenga su propio Estado, y en ese nuevo Estado-nación vasca se implante el socialismo"28.

Augusto Unceta Barrenechea era hijo del fundador de la fábrica de armas Astra, Unceta y Cía.

25 J. M. Portillo Valdés, Entre tiros e historia. La constitución de la autonomía vasca (1976-1979), Barcelona, Galaxia Gutenberg, 2018, p. 19.

26 "Ayer se presentó la UCD de Guipúzcoa", El País, 16 de octubre de 1977. "Se ha construido de abajo a arriba; pretende ser una opción mayoritaria junto al PNV y al PSOE, es autonomista, es un partido joven, condena la violencia con la máxima energía, [...], desea promover la cultura vasca, considera gravísima la situación de la economía guipuzcoana y, finalmente, se compromete a estrechar los lazos con las demás provincias vascas, de modo que se llegue a una UCD vasca, en la que Guipúzcoa vería con buenos ojos la integración de Navarra, aunque en el total respeto a su propia decisión"

27 "El logro del Estatuto de Gernika", Deia, 9 de febrero de 2020.

28 P. Ibarra Güell, La evolución estratégica de ETA, San Sebastián, Kriselu, 1987, p. 12. 


\section{LAS FUERZAS ANTIFRANQUISTAS Y EL TERROR}

La presión terrorista provocó el déficit del pluralismo vasco. Además, los partidos antifranquistas contribuyeron a deslegitimar al centro y a la derecha: mantuvieron que AP y UCD representaban el franquismo que se quería destruir. Desde su punto de vista, UCD no quería una reforma democrática sino la supervivencia franquista, con algunos retoques cosméticos. Según el esquema interpretativo que pervivió durante toda la Transición los avances democráticos llegaron gracias a la presión. La idea de que había que "seguir arrancando al Estado español lo que nos corresponde", se convirtió en un talismán interpretativo, sobre todo para el nacionalismo.

Pese a que el acoso terrorista estaba impidiendo la expresión de todo un ámbito político, ni nacionalistas ni socialistas advirtieron que las dificultades del centroderecha gravitaban también sobre toda la estructura política. Podía su equiparación con el franquismo, el enemigo al que combatir. El planteamiento relativizó el terrorismo, con efectos fatales.

Sucedía, además, que, a la salida del franquismo, el antifranquismo entendía que los terroristas formaban parte del juego político. A finales de la dictadura "la violencia se fue naturalizando, era otra estrategia a disposición, y ETA se sentaba en una unidad de acción con las mismas condiciones y aceptación, normalidad, que un partico político o asociación vecinal"29. Disfrutaba de una sorprendente aceptación.

\subsection{El nacionalismo "moderado" frente a la violencia}

La postura del PNV al respecto fue contundente. Cuando condenaba "la violencia", argumentaba que podía perjudicar el proceso que llevaba a la autonomía. No era un rechazo categórico. Vale de ejemplo el atentado en el que murió Unceta Barrenechea. EI PNV lo rechazaba porque "constituye un acto negativo en el avance del pueblo vasco en la conquista de sus derechos" ${ }^{30}$. Ese día el PNV evitó un comunicado conjunto con UCD, PSOE, AP y nacionalistas catalanes: casi todo el espectro parlamentario expresaba solidaridad con las víctimas y su defensa del proceso democrático y autonómico. Incluía también el compromiso de apoyar al Gobierno en la lucha contra el terrorismo, con una "Ley de Defensa de la Democracia contra el Terrorismo"31.

Tal planteamiento del PNV no fue fortuito, pues encajaba en las directrices ideológicas que orientaron su postura durante la Transición y que optó por emplear la expresión "lucha armada", en vez de "terrorismo", en consonancia con la actitud de ETA, que "rehuyó siempre el adjetivo 'terrorista' y prefirió enmarcar su 'lucha armada' en un conflicto secular [...] Lo suyo - sostenían- era un conflicto en toda regla"32.

En la primavera de 1977 el PNV actualizó su ideología y, desarrolló un radicalismo identitario, la idea de un pueblo vasco con una férrea personalidad propia —-"forma de ser"-, esencialista, en realidad formado por la comunidad nacionalista. A los ajenos a tal ámbito, "los residentes" les cabía un proceso de "nacionalización", con "un programa de culturización de este sector"33.

29 A. Rivera Blanco, "La construcción del "nosotros" vasco y su influencia en la violencia terrorista", en A. Rivera y E. Mateo (eds.), Verdaderos creyentes. Pensamiento sectario, radicalización y violencia, Madrid, La Catarata, 2018, p. 55.

30 "Información nacional", $A B C, 9$ de octubre de 1977. "Solamente sirve a los intereses de quienes desean desestabilizar el proceso político del país".

31 "Indignación de los partidos", $A B C, 9$ de octubre de 1977. El comunicado especificaba "la decidida voluntad de apoyar al Gobierno en su responsabilidad de poner fin a estos actos, incompatibles con el orden democrático".

32 M. Jiménez Ramos y J. Marrodán Ciordia, Heridos y olvidados. Los supervivientes del terrorismo en España, Madrid, La Esfera de los Libros, 2019, p. 47.

33 Euzko Alderdi Jeltzalea. Partido Nacionalista Vasco, Planteamientos político, socioeconómico y cultural, 
Al respecto, la perspectiva de la izquierda abertzale no era radicalmente diferente. Desde fines de los años sesenta ETA y su entono habían expresado sus propias exigencias para aceptar inmigrantes en su movimiento, necesidad derivada de su planteamiento socializante: "para que un inmigrante llegue a ser ciudadano vasco en pleno derecho [...] debía probar que no es enemigo real o potencial"34.

En cualquier caso, se derivaba un discurso agresivo construido sobre la tensión irreconciliable nosotros/ellos. Les cabía la consideración de "enemigos" a quienes fueran un obstáculo para la construcción nacional, por no aceptar la culturización y expresar su disconformidad con las propuestas nacionalistas. El pluralismo legítimo lo compondrían las distintas opciones nacionalistas.

El PNV situaba el origen del nacionalismo en la abolición de los fueros, calificada como "un hecho de fuerza", lo que justificaba que "muchos vascos no hayan echado en olvido esta invitación a la fuerza para recuperar su derecho"35.

Este esquema no experimentó grandes cambios durante la Transición. En esta argumentación, la violencia (el terrorismo) tiene raíces históricas y queda explicada por la "opresión permanente" 36 que los vascos sufren desde el XIX. La violencia vasca sería una respuesta secular ante un hecho violento. El franquismo constituyó un episodio más de este proceso, pero su brutalidad explicaría también que muchos vascos cogieran las armas y combatieran a quienes sostenían la represión permanente iniciada en la centuria anterior. "De nuestra absoluta sumisión a poderes extraños" se derivaba, entre otras "consecuencias funestas", "la desesperación de verse próximos al despojo de la propia identidad"37.

Para el PNV resultaba comprensible cualquier respuesta violenta contra la ocupación española del País Vasco. Era cuestión de opciones y de eficacia, no un problema ético. En vísperas de la autonomía aseguraba que había "dos estrategias posibles para el logro del autogobierno de nuestro País", entre ellas la "estrategia de la lucha armada"38. Era el éxito de la opción del PNV por "las vías políticas e institucionales" lo que invalidaba la otra vía, no su ilegitimidad. Al convocar su primera gran movilización contra la violencia, la seguía justificando: "Madrid sólo entiende el lenguaje de la fuerza [...] Y mientras este aserto esté en la mente de alguien, siempre habrá personas que se levanten con las armas"39.

\subsection{La adopción socialista de los planteamientos contra el terror}

EI PSOE -lo mismo que el PCE- no compartía tales planteamientos. Tras las primeras elecciones democráticas condenó específicamente el terrorismo, como tras la muerte de Unceta-Barrenechea, pero no fueron frecuentes posicionamientos de este tipo.

Bilbao, Editorial GEU, 1977, p. 173.

34 P. Unzueta, Los nietos de la ira. Nacionalismo y violencia en el País Vasco, Madrid, El País/Aguilar, 1988, p. 169

35 Euzko Alderdi Jeltzalea. Partido Nacionalista Vasco, Planteamientos... p. 37.

36 Comunicado del Euzkadi Buru Batzar del Partido Nacionalista Vasco ante el 25de octubre de 1839, octubre de 1977. "Al cumplirse el 138 aniversario de la ley 25 de Octubre de 1.839, que significó el despojo violento de las libertades del Pueblo Vasco".

37 Comunicado del Euzkadi Buru Batzar del Partido Nacionalista Vasco ante el 25 de octubre de 1839 , octubre de 1977.

38 EBB del PNV: El Partido Nacionalista Vasco ante la nueva etapa autonómica, noviembre de 1979.

39 "Mitin del PNV en Navarra sobre la Constitución", El País, 14 de octubre de 1978. Xabier Arzalluz insistía en el carácter intemporal de la reacción armada: "si piensan que esto es una innovación de ETA, están en un error, porque siempre ha habido gente que se ha levantado en Euskadi con las armas para luchar contra la opresión". 
Valga de ejemplo lo sucedido el trágico 2 de noviembre de 1978, tras la manifestación contra la violencia del 28 de octubre, cuando se iniciaba la campaña del referéndum constitucional. Ese día hubo tres atentados mortales. En los de Guernica y Lezo murieron dos jóvenes, carpintero y obrero, tachados de "chivatos" por ETA, y en Lezo un empresario que dos años antes se negó a pagar el "impuesto revolucionario", propiciando la detención del "negociador" Aya Zulaica. Hubo reacciones locales y UCD, destacó la actitud de José María Legasa que "supo hacer frente con valor, a la violencia, a la extorsión y a la coacción", llamando a posicionarse contra "la violencia y el terror" y a aislar a quienes optaban por la vía violenta, frente a quienes preferían la "pacífica, de diálogo"40.

La condena del PSOE, inequívoca, abundaba en circunloquios. Su argumentación presenta semejanzas con la del PNV, si bien designaba el asesinato de forma más precisa: "la muerte violenta y premeditada a manos de ETA". Rechazaba la eventual "institucionalización de los medios violentos" y criticaba las justificaciones basadas en "relaciones personales o de comportamientos políticos pasados o presentes de las víctimas", tales como la amistad con la policía. "No es el camino de las muertes fratricidas lo que va a permitir la consecución del autogobierno en Euskadi"41. Por contra, escasearon sus condenas cuando los atentados eran contra las fuerzas del orden. El Gobierno llegaba a incluir a los socialistas vascos entre "determinadas fuerzas políticas, que ven con el más absoluto distanciamiento, cuando no con indiferencia, el asesinato de miembros de seguridad"42.

En realidad, los planteamientos iniciales del PSOE frente al terror no fueron muy diferentes a los del PNV, para el que en materia de "autonomía y pacificación" no hubo "grandes disensiones" entre ambos partidos ${ }^{43}$. Podía la imagen por la que todos los grupos antifranquistas —incluyendo a ETA - compartían criterios básicos. También influía su construcción doctrinal, en la que estaba en primer plano el franquismo, que electoralmente identificaba con AP y UCD. "Los candidatos de Alianza Popular y la Unión de Centro Democrático son intercambiables"44, afirmaba Felipe González en San Sebastián antes de las elecciones de junio del 77.

La consideración de ETA como un factor político más persistió durante años. Por eso, las condenas del terrorismo no tuvieron prioridad en el discurso socialista, se centraron en las negativas consecuencias del terror o discutieron las razones por las que seleccionaba a sus víctimas. Quiso convencer sobre la inconveniencia de la violencia, más que condenarla. La primera declaración pública del Consejo General Vasco, en esta línea, también se refería indirectamente al terrorismo, pidiendo que "todos los sectores del pueblo vasco para que se incorporen a la actividad democrática", "llamando a la pacificación de Euskadi, al cese de la violencia" 45 , una suerte de tarea colectiva.

Indirecta e involuntariamente, concedía alguna legitimidad a la violencia política, desde el momento en que cabía debatir sobre su pertinencia, sobre si tenía alguna utilidad política o seleccionaba bien sus objetivos. Entendía que la salida "del clima de violencia" se produciría en virtud de cambios de carácter nacionalista, esto es, en función de avances autonómicos de los que se presentaba como valedor. En esta postura influía el sentir general,

40 "UCD-G pide posicionamientos personales ante la violencia", El Diario Vasco, 3 de noviembre de 1978.

41 "EI PSE-PSOE ante la espiral de violencia de ETA", El Diario Vasco, 4 de noviembre de 1978.

42 "Martín Villa acusa a la Consejería de Interior", El Diario Vasco, 19 de noviembre de 1978.

43 "El presidente del PNV valora positivamente el proyecto socialista para la pacificación", El País, 20 de octubre de 1979.

44 "Ataques al Centro y a Alianza Popular en el País Vasco", El País, 7 de junio de 1977.

45 J. M. López de Juan Abad, La autonomía vasca. Crónica del comienzo. El Consejo General Vasco, San Sebastián, Txertoa, 2011, p. 57. 
pues lo encontramos en todos los discursos de la época. También estaba presente su convicción de que, salvo en el independentismo, sus posiciones autonomistas no distaban de las nacionalistas, que así se convertían en la reivindicación de toda la oposición. Con alguna frecuencia expresaba distancias con respecto al tratamiento antiterrorista de UCD.

En los comienzos de la Transición procuró posicionamientos colectivos frente a la violencia. No avanzó una crítica salvo en circunstancias excepcionales como la de noviembre de 1978, tras el atentado a Epifanio Vidal, asesinado el 25 de octubre, obrero de la construcción, acusado de confidente y miembro de UGT. En el rechazo tenía más importancia repudiar tal motivo como causa del asesinato que la condena a este. En esto el PSOE respondía al clima general.

\section{EL AISLAMIENTO POLÍTICO DE UCD}

La izquierda no nacionalista inició los primeros posicionamientos colectivos contra ETA, pero las posturas antiterroristas del centro eran muy anteriores y más rotundas. A veces los antifranquistas excluían expresamente a UCD al posicionarse contra la violencia, como el enemigo al que se combatía, inductor de la violencia.

La primera manifestación contra ETA fue convocada por el PCE a mediados de 1978, pero unos meses antes, en enero, unos encuentros promovidos por la izquierda proponían a todos los partidos y sindicatos vascos una crítica colectiva a ETA ${ }^{46}$. Fue iniciativa conjunta de PCE, PSOE, UGT y CCOO. No proponían una rotunda condena a ETA, quizás para lograr un consenso amplio. Argumentaban que la lucha armada pudo tener justificación en épocas pasadas, pero no en el proceso democrático, en el que podía dificultar los dos principales objetivos, consolidar la democracia y erradicar los residuos dictatoriales. Por tanto, "pedimos unitaria y colectivamente a quienes practican la violencia armada, que depongan las pistolas y defiendan sus posiciones por medios democráticos y pacíficos"; llamaba también a posicionarse contra la violencia. Buscaba un respaldo social que pidiese el fin de la violencia armada.

Hubo representantes "de 22 partidos", casi todos de la extrema izquierda. La mayoría eran extraparlamentarios, pero también estaban el PNV y la UCD. Los partidos de la izquierda abertzale acudieron para comunicar inmediatamente que abandonaban la reunión. HASI, porque entendía que ETA era la violencia revolucionaria frente a la violencia institucional. LAIA, asegurando que las fuerzas de orden procedentes de la dictadura eran los "principales detentadores y principales responsables de la violencia existente en Euskadi". ANV aseguró no estar de acuerdo con los planteamientos de los convocantes. La reunión terminó cuando se produjo un enfrentamiento frontal, al pedir UCD que se excluyese a quienes no suscribieran la condena a ETA, lo que suscitó airadas reacciones. EI PNV no intervino, anunciando la publicación de sus posiciones, lo que implicaba su abandono de esta vía. La reunión había consistido en una exposición de los motivos que explicaban la acción de ETA y su justificación, con una parte del espectro político que lo apoyaba expresamente.

Los días siguientes se detallaron las posiciones:

a) EIA, el embrión de la Euskadiko Ezkerra que condenaría la violencia, proclamaba que "se abstiene de valorar públicamente las acciones armadas, tanto de ETA militar como político militar"; además, sostenía "que el único y principal responsable de la violencia en Euskadi es el Gobierno de la UCD". Sólo habría garantías para una acción democrática cuando se disolviesen los cuerpos represivos, hubiese una Constitución democrática que reconociera la autodeterminación e todas las libertades, así como un Estatuto de Autonomía "que satisfaga los intereses de la mayoría del pueblo".

46 "No hubo acuerdo", El Diario vasco, 31 de enero de 1978. 
b) La UCD apoyaba el documento presentado a la reunión, pero incluía dos objeciones: la violencia debía ser condenada "per se", por atentar contra los derechos humanos; y debía aislarse a los partidos "que favorecen y no condenan la violencia".

c) Para el PNV el documento era "unilateral", por no enfocar el problema en su totalidad. Sólo un "análisis serio" de las causas podía llevar a una "solución permanente y duradera". Expresaba el rechazo de la violencia echando mano del argumentario ya expuesto: podía perjudicar la vía autonomista, en particular provocando el rechazo hacia lo vasco en Navarra. Junto a ello, mostraba su equidistancia: estaba entre la violencia de ETA y la gubernamental; el "poder central" tenía que evitar que la violencia institucional produjese reacciones violentas, además de "devolver" los servicios de orden público. E incluía en el ámbito de la violencia institucional "el abuso del monopolio de los principales medios de comunicación, y la influencia abusiva de las clases dominantes", que podía influir - "quitar limpieza" - en cualquier consulta popular. EI PNV asumía así esquemas de corte revolucionario.

d) ETA solía participar en el debate político e hizo públicas sus posiciones. Rechazaba cualquier negociación con el Estado y aseguraba que se estaba gestando una "dictadura militar reformada" en la que los reformistas querían acabar con "la movilización obrera y popular". Expresaba su "objetivo independentista y socialista" y su programa, los puntos del KAS: amnistía total, salida del País Vasco de las fuerzas del orden, mejora de las condiciones de vida y de trabajo de las masas populares y un Estatuto de Autonomía que reconociese la soberanía nacional.

Con tales supuestos, apenas tuvo importancia la siguiente reunión ${ }^{47}$, a la que acudieron las cuatro organizaciones convocantes, así como UCD, DCV y EKA, el partido carlista, que se negó a tratar la cuestión de la violencia si antes no se abordaban "las responsabilidades del Gobierno de la UCD". PSOE y PCE desarrollaron una argumentación peculiar: la condena de la "violencia institucional", de la que responsabilizaba al Gobierno, y la propuesta de animar a posicionamientos colectivos contra la violencia. Lo primero buscaba atraer a quienes no asistían a la reunión, pero asumía también la equidistancia entre ETA y el Gobierno. UCD no admitió el planteamiento. Así, de estas iniciativas sólo salió el propósito de animar a reacciones sociales.

UCD quedaba estigmatizada como responsable de "la violencia institucional", concepto de los grupos revolucionarios y los próximos al terrorismo, pero compartido también por PNV, PSOE y PCE, que además asociaban el final de la violencia con los avances autonomistas. Los planteamientos que acompañaron a la convocatoria de la manifestación del 28 de octubre de 1978 confirman el aislamiento de UCD.

La convocó el PNV y en realidad se dirigía genéricamente contra la violencia, cuyo final se asociaba con cambios políticos. Lo resumía en su lema, "Por una Euskadi libre y en paz". Aún así, la izquierda abertzale la consideró "una auténtica declaración de guerra del PNV a ETA y KAS".

Pues bien: UCD hizo pública su intención de sumarse a la manifestación, pese a su ambigüedad. La iniciativa no fue bien acogida. El PNV le pidió que no participase. Aseguraba que la convocatoria buscaba denunciar la responsabilidad de UCD por negarse a soluciones políticas.

La manifestación se movía en la equidistancia que reparte culpas ${ }^{48}$. Según el PNV,

47 "Violencia: nueva reunión el lunes en Bilbao", El Diario Vasco, 7 de febrero de 1978.

48 "PNV pide a UCD que no participe", La Gaceta del Norte, 26 de octubre de 1978. "La convocatoria, además de expresar su propósito de erradicar la violencia, denuncia asimismo la responsabilidad del Gobierno por su sistemática negativa a adoptar soluciones políticas que contribuyan a acabar con el problema de la lucha armada". 
el Gobierno se negaba a devolver los Conciertos Económicos y "es el principal artífice de la desmembración territorial de Euzkadi", por la negativa de la UCD de Navarra a aceptar la integración en Euskadi. UCD decidió no asistir, lo que aparente y paradójicamente le apartaba del bloque contrario al terrorismo.

La ambigüedad frente a la violencia no la encontramos sólo entre los nacionalistas. UGT Euskadi — no las ejecutivas provinciales ni la federal—, sindicato no nacionalista, mostraba su oposición a la manifestación pacifista con argumentos parecidos a los de la izquierda abertzale. Desde su punto de vista, la violencia quedaba explicada —no justificada, matizapor la inhibición del Gobierno ante el problema vasco: orden público propio de la dictadura, no celebración de elecciones municipales y ausencia de competencias del Consejo General Vasco (aún no constituido). "La UGT de Euskadi denuncia que el desarrollo y consolidación del proceso democrático se traduce en una máxima autonomía, un compromiso por la paz y la solución de la crisis económica"49.

La Unión del Centro Democrático quedaba políticamente aislada.

\section{CONCLUSIÓN}

En el País Vasco de la Transición la presión terrorista condicionó la capacidad política de UCD, el partido que presidía los cambios, por su enorme impacto directo y porque actuó como catalizador de actitudes que retardaron el reconocimiento del pluralismo como un valor esencial de la democracia, concepto que no llegó a extenderse por todo el espectro político vasco.

La acción terrorista de ETA provocó la retracción política del centro-derecha e impidió que la UCD tuviese una implantación social en el País Vasco que se correspondiese con su verosímil peso electoral. El acoso del terror imposibilitó el funcionamiento de la UCD guipuzcoana, objeto sistemático de atentados mortales.

Algunas de las circunstancias agudizaron el impacto que tenían por sí mismas las actividades terroristas. Alcanzaron particular importancia los mecanismos que generó el terror, tanto los silencios sociales sobre los crímenes como la inacción ante los atentados. Se derivaban del miedo, de la aquiescencia o de la asunción de criterios por los que el asesinato o la amenaza constituían asuntos ajenos, de responsabilidades diversas, en las que el Gobierno y las autoridades tenían particular responsabilidad, igual o mayor que los terroristas. No era propiamente neutralidad sino asunción de comportamientos inducidos por la organización terrorista y su entorno.

El impacto del terrorismo significó también que se propagaran los mecanismos que aislaban socialmente al señalado por ETA o el "algo habrá hecho" que estigmatizaba a la víctima y que resultó fatal en el caso de la UCD, por estigmatizar a todo un ámbito político. Implicó a su vez un derrumbamiento ético de la sociedad vasca, agravado por el distanciamiento moral al que procedieron algunos partidos y dirigentes eclesiásticos.

La amenaza terrorista dio virulencia a las actitudes de partidos antifranquistas que, discrepando de ETA, asumieron algunos conceptos provenientes de este ámbito o de los grupos antisistema, tales como la idea de que existía una lucha entre la violencia revolucionaria y la institucional. El nacionalismo moderado, por otra parte, mostraba comprensión respecto a la lucha armada, aunque discrepaba de ella, dándole alguna legitimidad en un esquema que entendía como enemigos a los no insertos en su concepto de pueblo vasco. Socialistas y nacionalistas asistieron con cierta indiferencia al acoso que sufría la derecha y la UCD, sin caer en la cuenta de que formaban parte del pluralismo vasco que era necesario sostener a la hora de construir la democracia.

49 "Discrepancias de UGT sobre la manifestación", El Diario Vasco, 26 de octubre de 1978. 
Este aislamiento y debilidad de UCD, en unos momentos de convulsiones sociales en medio de las cuales resultaban urgentes medidas descentralizadoras en el País Vasco, gestó una situación peculiar. Sin capacidad de sostener socialmente unos planteamientos propios sobre la cuestión autonómica, le resultaba imprescindible contar con apoyos políticos sólidos, que validasen las iniciativas autonómicas. A la postre, tal apoyo fue el PNV, cuyos planteamientos autonomistas eran compartidos en buena medida por los socialistas.

La evolución de los acontecimientos generados por el terrorismo y la necesidad de asentar localmente la Transición privilegió al PNV y su capacidad de presión política. Por esta vía, las opciones descentralizadoras desembocaron en el País Vasco en un estatuto rotundamente nacionalista, con gran influencia posterior en otras autonomías. Esta continuación de la historia desborda las pretensiones de este artículo.

\section{BIBLIOGRAFÍA}

Alonso, R., Domínguez, F. y García Rey, M., Vidas rotas. Historia de los hombres, mujeres y niños víctimas de ETA, Madrid, Espasa, 2010.

Angulo, G., La persecución de ETA a la derecha vasca. Amenazas, exilio, extorsión y asesinatos, Córdoba, Almazara, 2018.

Baz, E., Los niños de Lemóniz, Barcelona, Espasa, 2019.

Fernández Soldevilla, G., Héroes, heterodoxos y traidores. Historia de Euskadiko Ezkerra (1974-1994), Madrid, Tecnos, 2013.

- La voluntad del Gudari. Génesis y metástasis de la violencia de ETA, Madrid, Tecnos, 2016.

Fernández Soldevilla, G. y Domínguez, F., Pardines. Cuando ETA empezó a matar, Madrid, Tecnos, 2018.

Fusi, J. P., y Pérez, J. A. (eds.), Euskadi 1960-2011, Madrid, Biblioteca Nueva, 2017.

Garmendia, J. M., Historia de ETA, San Sebastián, R\&B Ediciones, 1996.

Ibarra Güell, P., La evolución estratégica de ETA, San Sebastián, Kriselu, 1987.

Jiménez Ramos, M. y Marrodán Ciordia, J., Heridos y olvidados. Los supervivientes del terrorismo en España, Madrid, La Esfera de los Libros, 2019.

López de Juan Abad, J. M., La autonomía vasca. Crónica del comienzo. El Consejo General Vasco, San Sebastián, Txertoa, 2011.

López Romo, R. (ed.), Memorias del terrorismo en España, Madrid, La Catarata, 2018.

- Informe Foronda. Los contextos históricos del terrorismo en el País Vasco y la consideración social de las víctimas, 1960-2010, Vitoria-Gasteiz, 2014.

Merino Pacheco, F. J., La izquierda radical ante ETA. ¿El último espejismo revolucionario de Occidente?, Bilbao, Bakeaz, 2011.

Montero, M., El sueño de la libertad. Mosaico vasco de los años del terror, Oviedo, Nobel, 2018.

- Voces vascas. Diccionario de uso, Madrid, Tecnos, 2014.

Morán, G., Los españoles que dejaron de serlo. Cómo y por qué Euskadi se ha convertido en la gran herida histórica de España, Barcelona, Planeta, 1983.

- Testamento vasco, Barcelona, Espasa Calpe, 1988.

Portillo Valdés, J. M., Entre tiros e historia. La constitución de la autonomía vasca (19761979), Barcelona, Galaxia Gutenberg, 2018.

Rivera, A. (ed.), Nunca hubo dos bandos. Violencia política en el País Vasco, 1975-2011, Granada, Comares, 2019.

Rivera, A. y Mateo, E. (eds.), Verdaderos creyentes. Pensamiento sectario, radicalización y violencia, Madrid, La Catarata, 2018. 
Silva, L., Sánchez, M. y Araluce, G., Sangre, sudor y paz. La guardia civil contra ETA, Barcelona, Península, 2017.

Ugarte Gastaminza, J. (coord.), La bolsa y la vida. La extorsión y la violencia de ETA contra el mundo empresarial, Madrid, La Esfera de los Libros, 2017. 